NATIONAL LABORATORY

\title{
Heavy and Overweight Vehicle Defects \\ Interim Report
}

\section{November 2012}

Prepared by

Adam Siekmann

Gary Capps

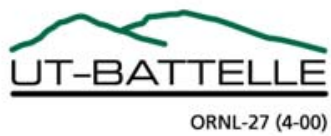


Energy and Transportation Science Division

\title{
HEAVY AND OVERWEIGHT VEHICLE DEFECTS INTERIM REPORT
}

\author{
Adam Siekmann \\ Gary Capps
}

Date Published: November 2012

Prepared by OAK RIDGE NATIONAL LABORATORY

Oak Ridge, Tennessee 37831-6283 managed by

UT-BATTELLE, LLC

for the

U.S. DEPARTMENT OF ENERGY

under contract DE-AC05-00OR22725 


\section{CONTENTS}

Page

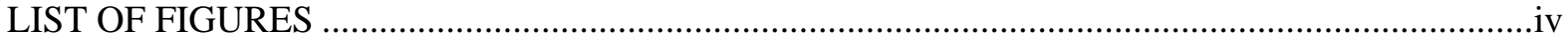

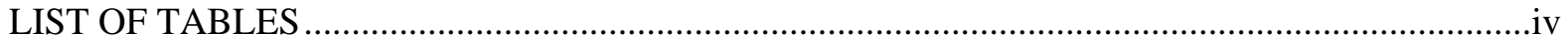

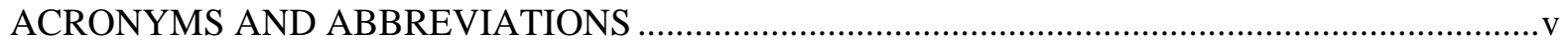

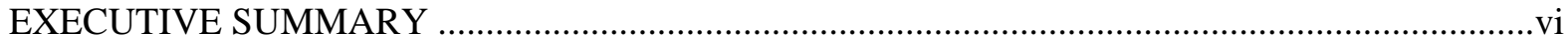

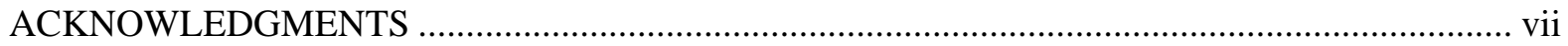

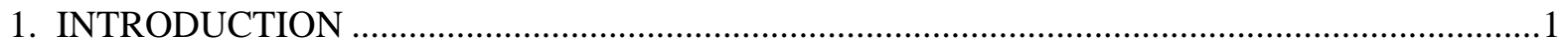

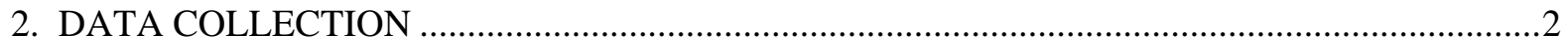

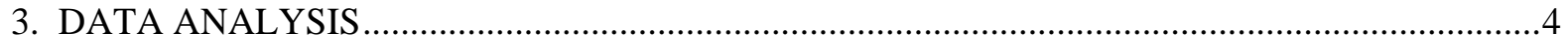

3.1 TENNESSEE OVERWEIGHT VEHICLE DEFECTS …......................................................

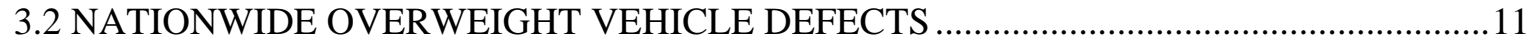

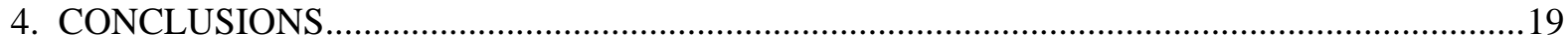

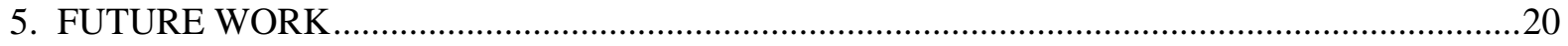




\section{LIST OF FIGURES}

Page

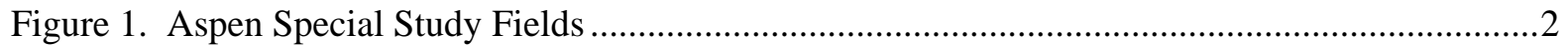

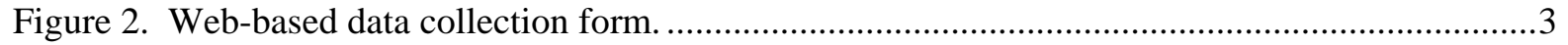

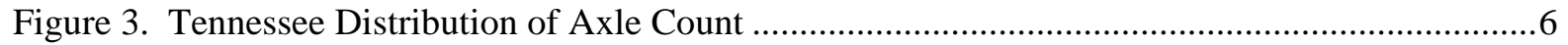

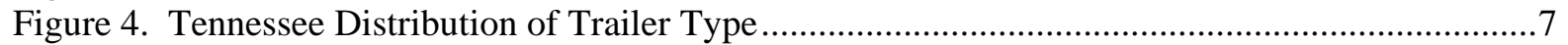

Figure 5. Tennessee Distribution of Gross Vehicle Weight .............................................................. 7

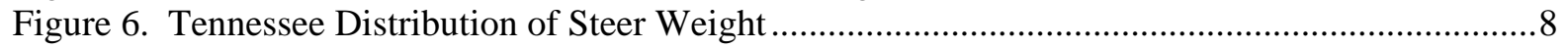

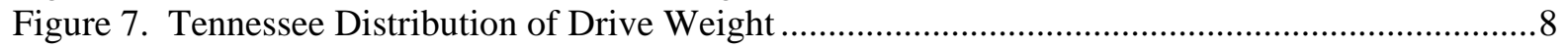

Figure 8. Tennessee Distribution of Trailer Weight ..........................................................................

Figure 9. Tennessee Distribution of Weight Over on Axle Groups....................................................10

Figure 10. Tennessee Distribution of Weight Over Gross .................................................................10

Figure 11. Nationwide Distribution of Gross Vehicle Weight ...........................................................17

Figure 12. Nationwide Out-of-Service Rate by Gross Vehicle Weight .............................................18

Figure 13. ORNL-Developed Online Analysis Tool .......................................................................20

\section{LIST OF TABLES}

Table 1. Tennessee Overweight Out-of-Service Rates ................................................................

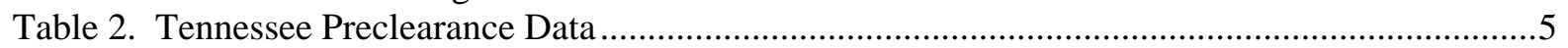

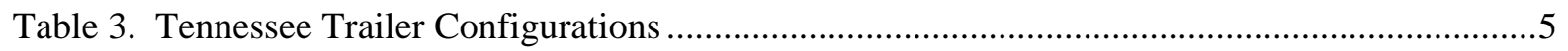

Table 4. Tennessee Overweight Location.................................................................................

Table 5. Tennessee Average Weight Over Legal Limit..................................................................10

Table 6. Tennessee Average Weight Over Legal Limit, Specific Locations .......................................10

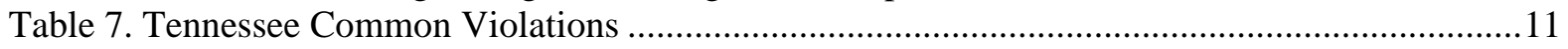

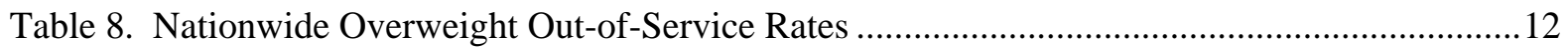

Table 9. Nationwide Detailed Out-of-Service Rates...................................................................12

Table 10. Nationwide CSA Vehicle Maintenance BASIC Percentile Rank .......................................13

Table 11. Nationwide CSA Vehicle Maintenance BASIC Percentile Rank Out-of-Service Rates .....14

Table 12. Nationwide CSA Crash Indicator Percentile Rank ........................................................14

Table 13. Nationwide Primary Cause of Out-of-Service CMV ....................................................15

Table 14. Nationwide Out-of-Service Violations .................................................................................

Table 15. Nationwide Common Out-of-Service Violations ...........................................................16

Table 16. Nationwide Out-of-Service Rate of Vehicles With Weight Violations ...............................18 


\section{ACRONYMS AND ABBREVIATIONS}

Term

CMV

CMVRTC

CSA

CVSA

GCW

GVW

FHWA

FMCSA

IS

$\mathrm{lb}$

NAS

OOS

ORNL

\section{Definition}

Commercial Motor Vehicle

Commercial Motor Vehicle Roadside Technology Corridor

Compliance, Safety, Accountability (FMCSA Initiative)

Commercial Vehicle Safety Alliance

Gross Combination Weight

Gross Vehicle Weight

Federal Highway Administration

Federal Motor Carrier Safety Administration

Inspection Station

Pounds

North American Standard

Out-of-Service

Oak Ridge National Laboratory 


\section{EXECUTIVE SUMMARY}

The Federal Highway Administration (FHWA), along with the Federal Motor Carrier Safety Administration (FMCSA), has an interest in overweight commercial motor vehicles, how they affect infrastructure, and their impact on safety on the nation's highways. To assist both FHWA and FMCSA in obtaining more information related to this interest, data was collected and analyzed from two separate sources. A large scale nationwide data collection effort was facilitated by the Commercial Vehicle Safety Alliance as part of a special study on overweight vehicles and an additional, smaller set, of data was collected from the state of Tennessee which included a much more detailed set of data.

Over a six-month period, 1,873 Level I inspections were performed in 18 different states that volunteered to be a part of this study. Of the 1,873 inspections, a vehicle out-of-service (OOS) violation was found on $44.79 \%$ of the vehicles, a rate significantly higher than the national OOS rate of $27.23 \%$. The main cause of a vehicle being placed OOS was brake-related defects, with approximately $30 \%$ of all vehicles having an OOS brake violation. Only about $4 \%$ of vehicles had an OOS tire violation, and even fewer had suspension and wheel violations.

Vehicle weight violations were most common on an axle group as opposed to a gross vehicle weight violation. About two thirds of the vehicles cited with a weight violation were overweight on an axle group with an average amount of weight over the legal limit of about 2,000 lbs.

Data collection is scheduled to continue through January 2014, with more potentially more states volunteering to collect data. More detailed data collections similar to the Tennessee data collection will also be performed in multiple states. 


\section{ACKNOWLEDGMENTS}

The Commercial Motor Vehicle Roadside Technology Corridor team would like to thank the Tennessee Highway Patrol and the staff of the Coffee County, Greene County, Haywood County, Knox County, and Robertson County Commercial Motor Vehicle Inspection Stations in Tennessee for their support of this research. Without their effort in collecting the required data, this research would not have been possible.

The team would also like to thank the Commercial Vehicle Safety Alliance for facilitating the collection of inspections, and also the states that volunteered to inspect vehicles as part of this data collection effort. 


\section{INTRODUCTION}

In order to preserve infrastructure and keep commercial motor vehicles (CMVs) moving efficiently, states must comply with federal size and weight standards which are certified by the Federal Highway Administration (FHWA). The Bridge Formula Weights, which is based on the number of axles a vehicle has and the spacing between them, establishes the maximum gross vehicle weight (GVW) and axle weight of a vehicle. Interstate vehicles are allowed to weigh up to 80,000 lb GVW, with single axles supporting a maximum of 20,000 lb, tandem axles supporting 34,000 lb, and tri-axles supporting up to $54,000 \mathrm{lb}$ without a permit. All states are required to follow the Bridge Formula Weights for interstate vehicles. Also, permitted loads are typically allowed for well over 100,000 lb GVW based on the number of axles and permit type, with up to 40,000 lb and 60,000 lb on tandem and tri-axle configurations respectively.

Typically, CMVs that enter the inspection station (IS) and are overweight on one or more axles, are likely exceeding their allowed GVW, or are permitted and do not receive a North American Standard (NAS) Level I (vehicle and driver) or Level II (driver and vehicle walk-around) safety inspection. This is due primarily to states' lack of inspection resources and, in part, to the fact that in many cases overweight vehicles are also oversized and/or on specialized trailers that are not practically accessible for inspection. In some cases states combine the overweight assessment with an NAS Level III (driver only inspection). Because of this practice very little is known about the condition, relative to safety, of the CMV operating at a weight above the legal limit.

In 2011, the Oak Ridge National Laboratory (ORNL) conducted a preliminary study for the Federal Motor Carrier Safety Administration (FMCSA) to collect demographic information on overweight and permitted vehicles in order to develop future strategies for collecting overweight vehicle data. This study revealed that the vast majority of overweight vehicles consisted of five axles or more, and although they were very rarely over the legal GVW limit, they were typically overweight on at least one axle group (82.2\% of the time for five-axle vehicles). Although there was not enough inspection data collected during this preliminary study to be statistically significant, the study showed that $75 \%$ of the eight overweight vehicles given a Level I vehicle inspection were placed Out-of-Service (OOS) for a vehicle related defect.

Shortly after the preliminary study, ORNL collected Level I inspection data on vehicles in the state of Tennessee in which 289 overweight vehicles were inspected. Of those 289 inspections, 129 (43.25\%) were OOS for having a vehicle violation, a rate significantly above the national average of $27.23 \%$. This high OOS rate and other data collected during this previous effort were driving factors for the continuation of the collection of vehicle inspections of overweight vehicles from more states as part of a FHWA study. 


\section{DATA COLLECTION}

The data collection was broken into two separate and distinct efforts. The first effort consisted of collecting detailed information on inspected vehicles which is not readily available from a normal NAS Level I inspection. Details such as tractor-trailer configuration, individual axle weights, presence of preclearance technology, and exact location of any overweight violation are examples of this type of data. The second effort was part of a Commercial Vehicle Safety Alliance (CVSA) special study in which volunteer states recorded only the GVW and permit status of any overweight vehicle given an NAS Level I inspection.

The methodologies for both efforts were similar. For the CVSA data collection effort, a certified inspector would perform Level I inspections on overweight CMVs as part of their normal operation and recorded the GVW of the CMV and also if the vehicle was permitted in the special study fields of Aspen. These special study fields of Aspen are shown in Figure 1. In Tennessee, inspections of overweight vehicles were performed at both the Knox and Greene County ISs ${ }^{1}$. At the Knox County IS a certified inspector would perform a Level I inspection on overweight vehicles with preclearance technology off. The Greene County IS performed overweight inspections as part of their normal operation, but preclearance technology may or may not have been intentionally turned off as part of this effort at the time of selection. Inspection data from Tennessee was recorded in Aspen as well as a special online fillable form developed by ORNL to capture more detailed data about the vehicle. Using this form, researchers are able to get specific weight data as well as other information that is not available from just a Level I inspection, e.g., if a vehicle had preclearance technology onboard. The online fillable form that was used in Tennessee is shown in Figure 2.

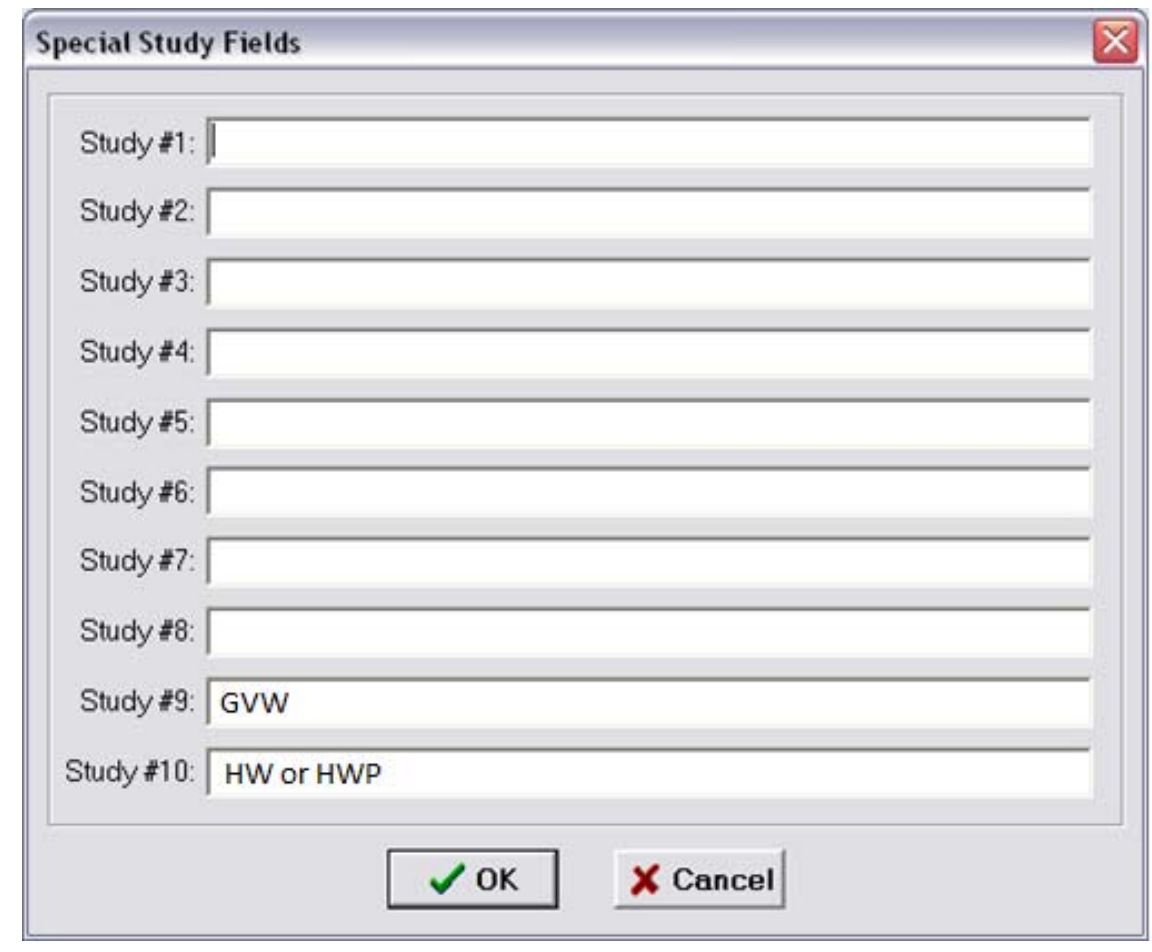

Figure 1. Aspen Special Study Fields

\footnotetext{
${ }^{1}$ Due to vehicle selection methodologies in Tennessee differing from normal protocol, it is not recommended that any Tennessee inspection data be compared with other State or national averages.
} 


\begin{tabular}{|c|c|c|}
\hline \multicolumn{3}{|c|}{ General Information } \\
\hline Date & & Additonal Comments \\
\hline \multicolumn{2}{|l|}{ Time } & \multirow[t]{2}{*}{$\underline{\Delta}$} \\
\hline State & Tennessee & \\
\hline \multirow[t]{2}{*}{ Officer } & & \multirow[b]{2}{*}{ Need Help? } \\
\hline & & \\
\hline \multicolumn{3}{|l|}{ Vehicle Information } \\
\hline Trailer Type & \multicolumn{2}{|c|}{ (Flatbed, box, car-hauler, specialty rig, etc.) } \\
\hline Cargo & & (General description - pipe, equipment, steel, concrete, etc.) \\
\hline Permit & \multicolumn{2}{|l|}{$\ulcorner$ Permitted Overweight } \\
\hline Transponder & \multicolumn{2}{|l|}{$\ulcorner$ PrePass $Г$ NORPASS } \\
\hline Carrier Operation & \multicolumn{2}{|l|}{ Interstate $\triangle$ Intrastate } \\
\hline
\end{tabular}

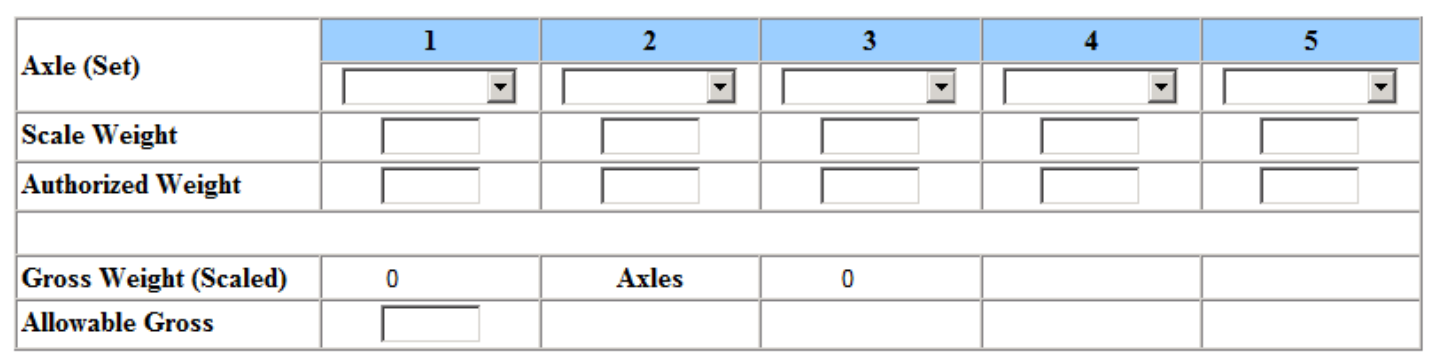

\begin{tabular}{|l|l|l|}
\hline \multicolumn{2}{|l|}{ Inspection Information } & \multicolumn{2}{|l|}{} \\
\hline ASPEN Report ID & \multicolumn{1}{|c|}{$\Gamma$ PBBT Test (Optional, not required) } \\
\hline PBBT Scores (if applicable) & Left Wheel-Ends & Right Wheel-Ends \\
\hline
\end{tabular}

Figure 2. Web-based data collection form.

For both data collection activities, Aspen data was received for each inspection performed. The Tennessee data came from the Tennessee Department of Safety and Homeland Security, and the CVSA inspection data came from FMCSA. 


\section{DATA ANALYSIS}

The data analysis was broken up based on the two different efforts to accommodate the depth of information available from the online form used in Tennessee. Also, the inspection information from both efforts was received from different sources so they consisted of different formats and contained different fields. For both efforts, all the inspections are Level I inspections and OOS rates are only based on vehicle violations and not driver violations.

All data collected was processed using ORNL developed software to calculate violations, OOS rates and other relevant data that was included in both the online fillable form and the Aspen reports.

\subsection{TENNESSEE OVERWEIGHT VEHICLE DEFECTS}

Table 1 shows the OOS rates for the overweight vehicles inspected at the Knox and Greene County ISs. $44.72 \%$ of the 398 vehicles inspected were placed OOS for a vehicle defect. This number is nearly twice the national and state OOS rate (27.23\% and $23.60 \%$ respectively for 2011$)$. Also, on average CMVs that are inspected at the Greene County and Knox County ISs are placed OOS a combined 28\% of the time (overweight and not overweight). While this suggests that there may be a correlation between overweight vehicles and OOS violations for this specific stream of vehicles, it cannot be concluded because the selection methodology is different for each of the statistics.

Table 1. Tennessee Overweight Out-of-Service Rates

\begin{tabular}{|c|rrr|rcc|}
\hline Axles & Number CMVs & OOS & OOS Rate & Permitted & Permitted OOS & Permitted OOS Rate \\
\hline $\mathbf{2}$ & 2 & 1 & $50.00 \%$ & 0 & 0 & $0.00 \%$ \\
\hline $\mathbf{3}$ & 5 & 1 & $20.00 \%$ & 0 & 0 & $0.00 \%$ \\
\hline $\mathbf{4}$ & 10 & 7 & $70.00 \%$ & 0 & 0 & $0.00 \%$ \\
\hline $\mathbf{5}$ & 373 & 165 & $44.24 \%$ & 18 & 10 & $55.56 \%$ \\
\hline $\mathbf{6}$ & 5 & 3 & $60.00 \%$ & 3 & 1 & $33.33 \%$ \\
\hline $\mathbf{7}$ & 3 & 1 & $33.33 \%$ & 3 & 1 & $33.33 \%$ \\
\hline Total & $\mathbf{3 9 8}$ & $\mathbf{1 7 8}$ & $\mathbf{4 4 . 7 2 \%}$ & $\mathbf{2 4}$ & $\mathbf{1 2}$ & $\mathbf{5 0 . 0 0 \%}$ \\
\hline
\end{tabular}

Tennessee and other states that use preclearance technology allow carriers in good standing to bypass ISs at a rate determined by the operators of the IS. In states that have not deployed mainline Weigh in Motion technology in concert with their preclearance technology (such as Tennessee), an overweight vehicle could be allowed to bypass. This is evident in that $42.60 \%$ of the overweight vehicles with preclearance technology, which normally may have bypassed the IS altogether, were placed OOS for a vehicle violation. While preclearance systems greatly benefit drivers and carriers and can increase the safety of the motoring public by reducing the number of CMV entering and exiting ISs, they can create potential safety hazards when overweight vehicles and vehicles with faulty equipment are allowed to bypass (due to the absence of mainline weight screening). Table 2 shows the OOS rate for vehicles with and without preclearance technology. Also, preclearance vehicles may knowingly run overweight since the likelihood of being weighed is usually much less than vehicles without preclearance technologies. 
Table 2. Tennessee Preclearance Data

\begin{tabular}{|c|cccccc|}
\hline Preclearance & Number & OOS & $\begin{array}{c}\text { Overweight } \\
\text { Axle }\end{array}$ & $\begin{array}{c}\text { Overweight } \\
\text { Gross }\end{array}$ & $\begin{array}{c}\text { Overweight } \\
\text { Both }\end{array}$ \\
\hline Yes & 169 & $42.60 \%$ & 160 & 25 & 22 \\
\hline No & 229 & $46.29 \%$ & 199 & 55 & 48 \\
\hline Total & $\mathbf{3 9 8}$ & $\mathbf{4 4 . 7 2 \%}$ & $\mathbf{3 5 9}$ & $\mathbf{8 0}$ & $\mathbf{7 0}$ \\
\hline
\end{tabular}

The type of trailer axle configuration of a CMV is important in determining the gross and axle weight a vehicle is allowed. As previously stated, single axles are allowed up to 20,000 lb, tandem axles up to $34,000 \mathrm{lb}$ (40,000 lb if spread axle in Tennessee) and up to 54,000 lb on tri-axle groups. Table 3 shows the types of tractor-trailer configurations that were inspected as a part of this effort. As expected, the majority of vehicles were 5-axle tractor-trailers with tandem drive and tandem trailer axle groups; this configuration allows for up to 80,000 lb GVW.

Table 3. Tennessee Trailer Configurations

\begin{tabular}{|c|lrc|}
\hline No. Axles & \multicolumn{1}{|c}{ Type of Vehicle } & Number CMVs Inspected & Percent of All CMVs \\
\hline $\mathbf{2}$ & Straight Truck & 2 & $0.50 \%$ \\
\hline \multirow{2}{*}{3} & Single Drive and Trailer & 1 & $0.25 \%$ \\
\cline { 2 - 4 } & Tandem Drive Axle & 4 & $1.01 \%$ \\
\hline \multirow{3}{*}{4} & Single Axle Trailer & 1 & $0.25 \%$ \\
\cline { 2 - 4 } & Dual Tandem Axles & 1 & $0.25 \%$ \\
\cline { 2 - 4 } & Single Drive Axle w/ Tandem Trailer & 8 & $2.01 \%$ \\
\hline \multirow{2}{*}{5} & Tandem Trailer & 330 & $82.91 \%$ \\
\cline { 2 - 4 } & Spread Axle Trailer & 38 & $9.55 \%$ \\
\cline { 2 - 4 } & Double Trailer & 5 & $1.26 \%$ \\
\hline \multirow{2}{*}{$6+$} & Tri Axle Trailer & 5 & $1.26 \%$ \\
\cline { 2 - 4 } & Tri Axle Drive w/ Tri Axle Trailer & 398 & $0.75 \%$ \\
\hline \multirow{2}{*}{ Total } & & & $\mathbf{1 0 0 . 0 0 \%}$ \\
\hline
\end{tabular}


Figure 3 shows the distribution of CMVs by axle count which were recorded in the Tennessee Level 1 inspections. Again, as previously shown in Table 3, 5-axle vehicles represent $94 \%$ of the inspected vehicles.

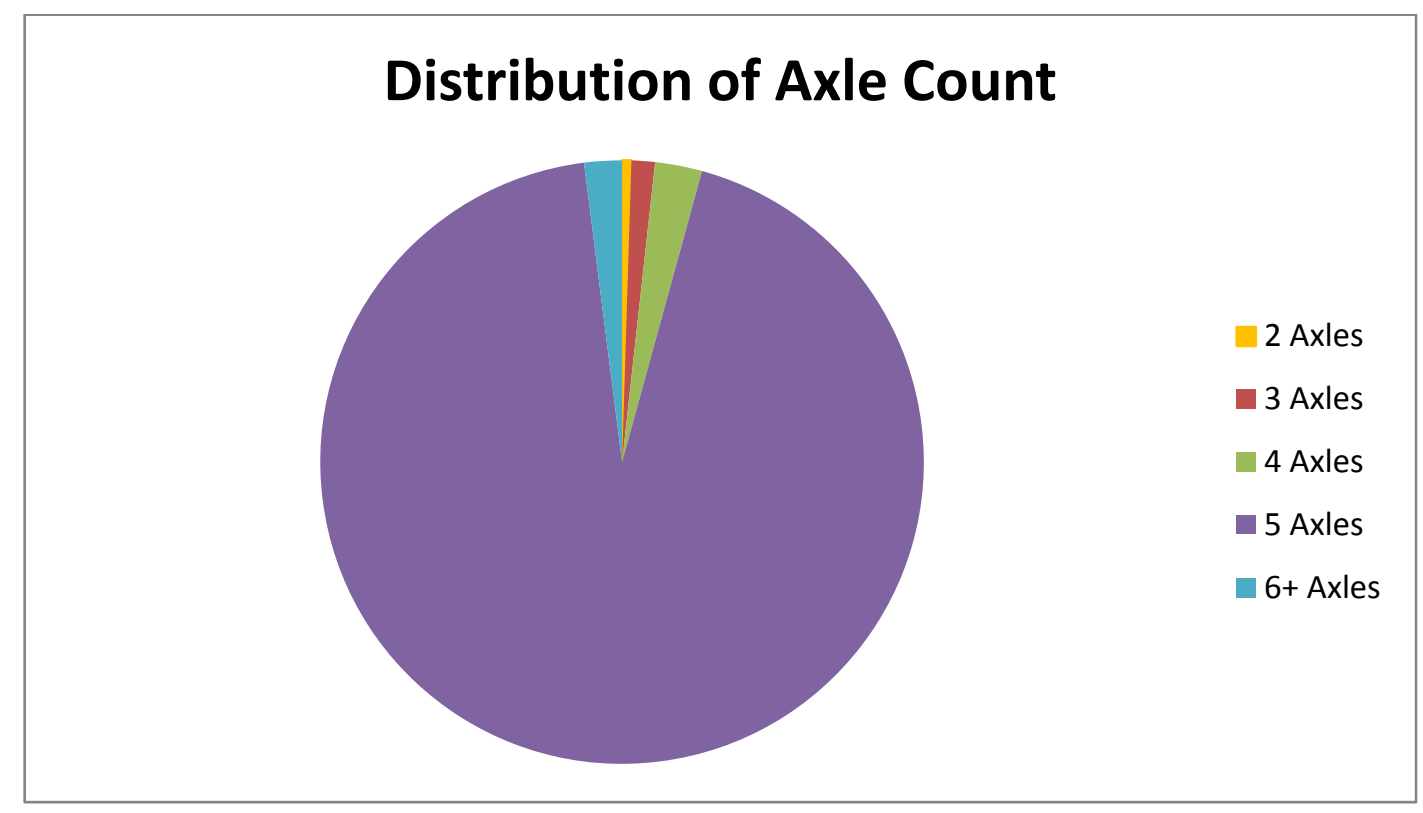

Figure 3. Tennessee Distribution of Axle Count

Figure 4 shows the trailer type distribution of inspected vehicles in Tennessee. The trailer type represents what type of cargo is typically being carried and what type of violations may accompany those violations. The majority of the trailers inspected during this effort were box trailers which typically carried general freight. Flatbed trailers often carried large machinery or equipment which can be susceptible to load securement and size violations as well as axle weight violations. Dump-type trailers and tankers made up $10 \%$ of the trailers inspected and the type of material they were hauling varied. The Other category represents car haulers, specialty trailers, low boys (low clearance trailers), and other uncommon trailer types. 


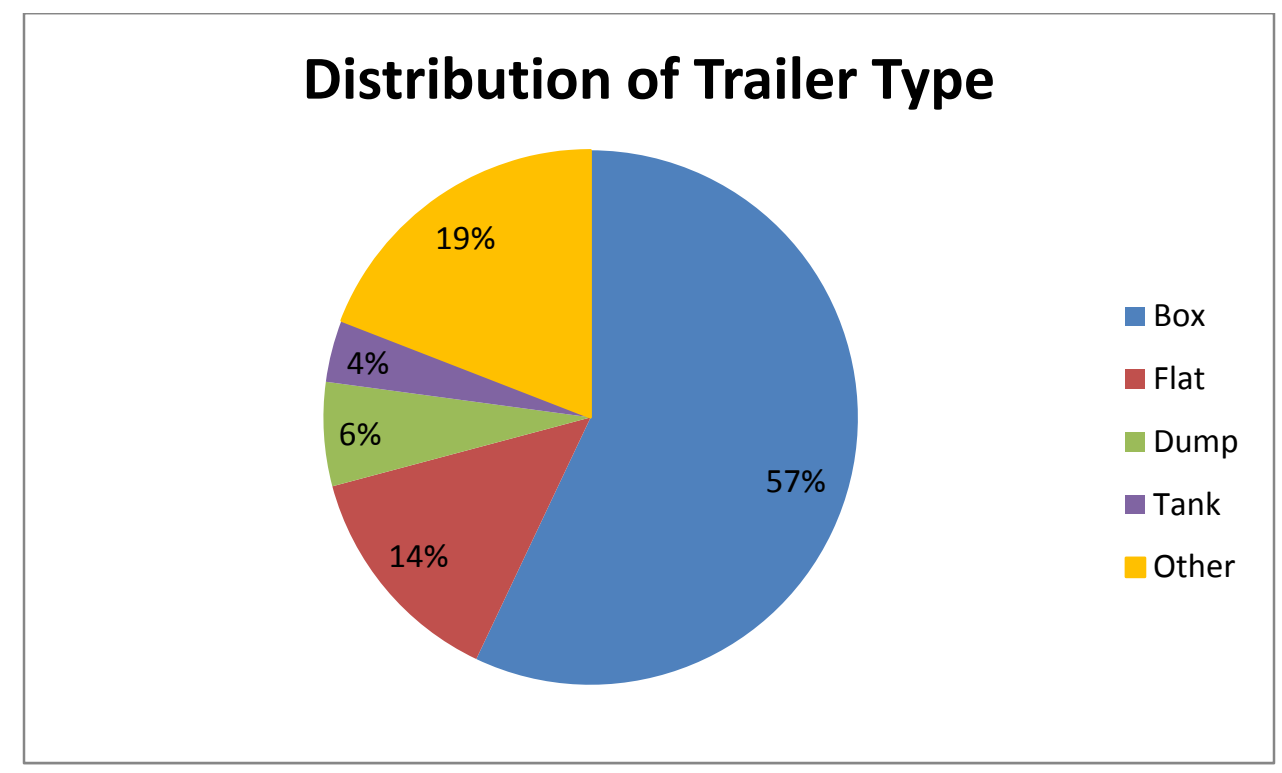

Figure 4. Tennessee Distribution of Trailer Type

Figure 5 shows the distribution of GVWs for both permitted and not permitted vehicles. Nearly $90 \%$ of all the vehicles inspected were in the 70,000 lb to 85,000 lb range and about 70\% below the 80,000 lb gross limit for most five-axle vehicles. Due to the configuration of the Knox County IS, it was not possible to weigh three of the vehicles.

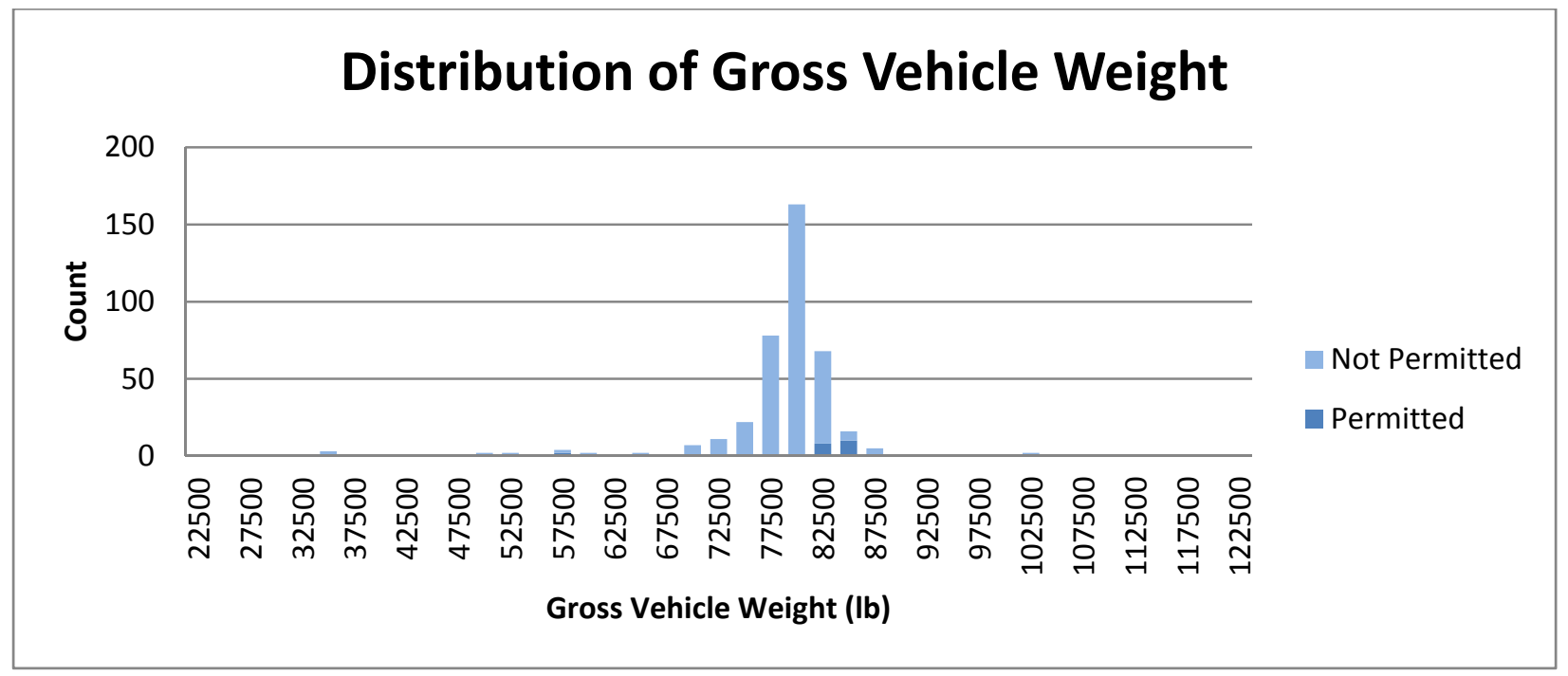

Figure 5. Tennessee Distribution of Gross Vehicle Weight

Figure 6, Figure 7, and Figure 8 show the distribution of weight on the steer, drive and trailer axles respectively. Since no cargo is typically carried in the front of the vehicle, the steer weight will rarely exceed 12,000 lb to 14,000 lb. Drive weight axles include both tandem and single axle configurations and nearly half of the vehicles were over the legal limit on the drive axles. Similarly for the trailer axles, which include multiple trailers in some cases, over half of the trailer axles were over the legal limit. 


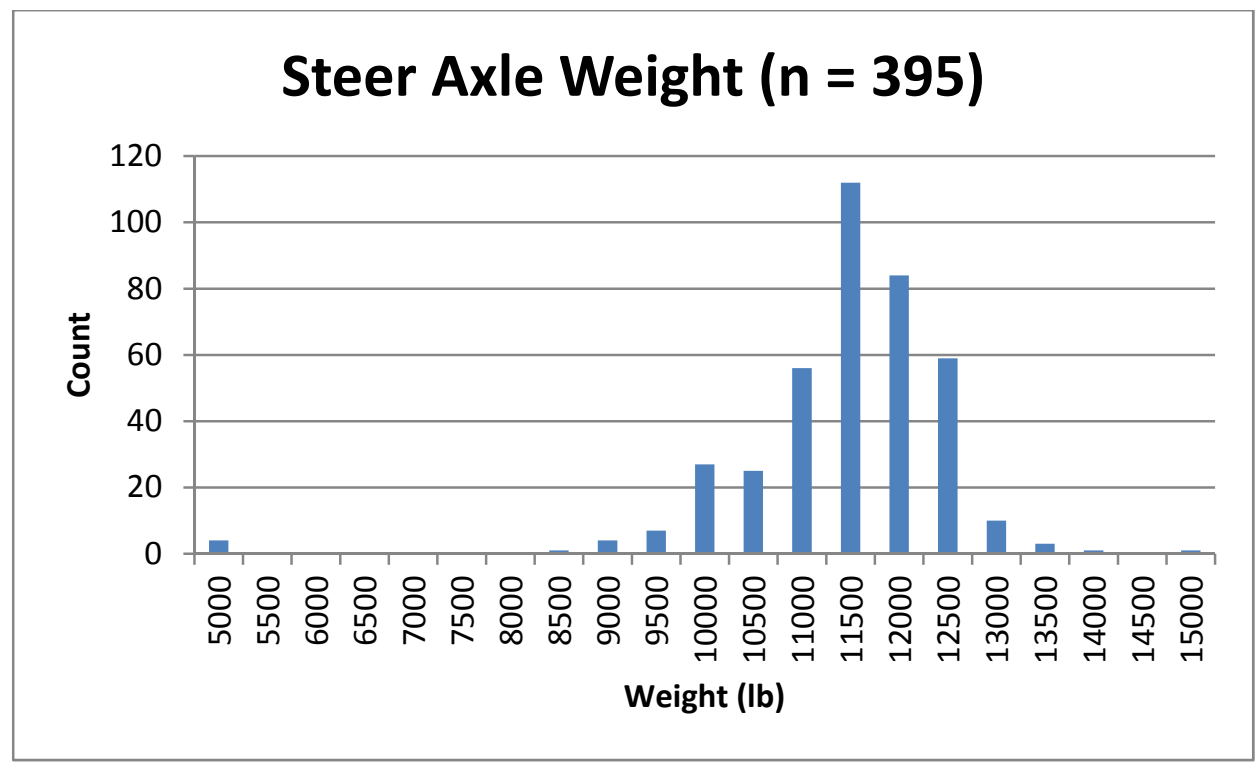

Figure 6. Tennessee Distribution of Steer Weight

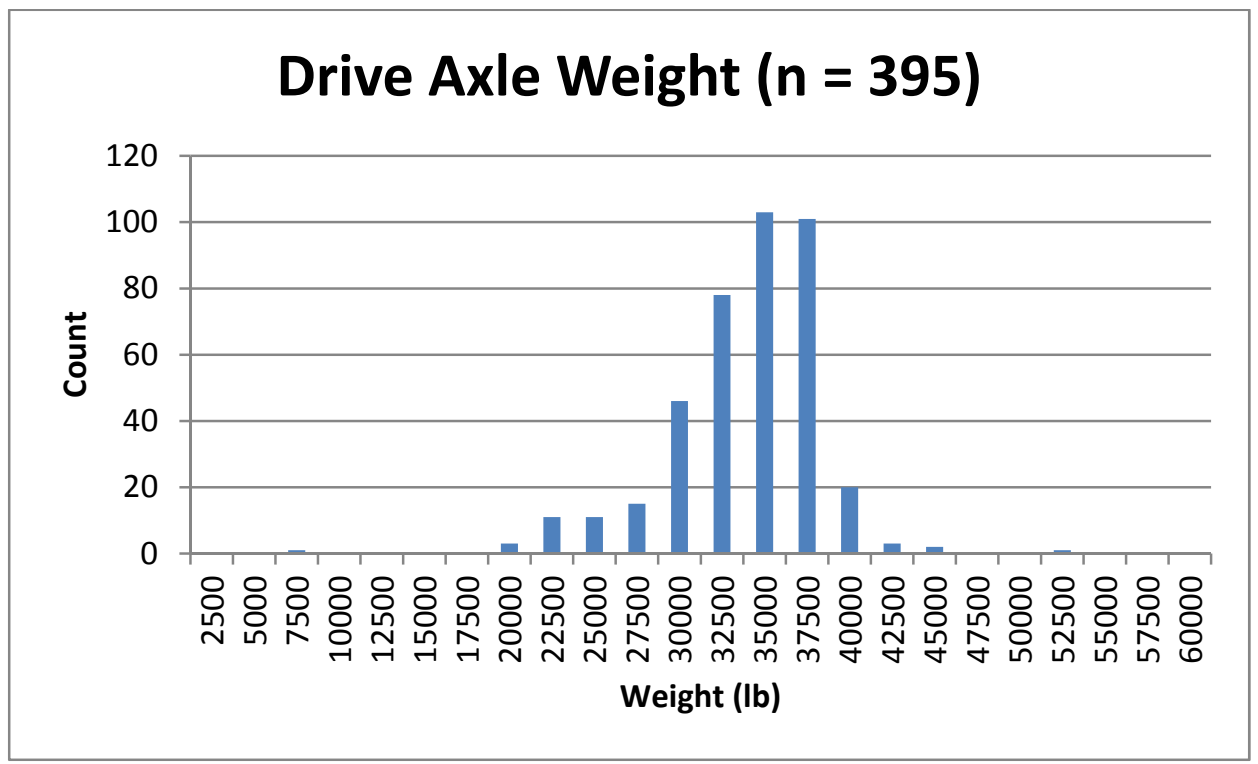

Figure 7. Tennessee Distribution of Drive Weight 


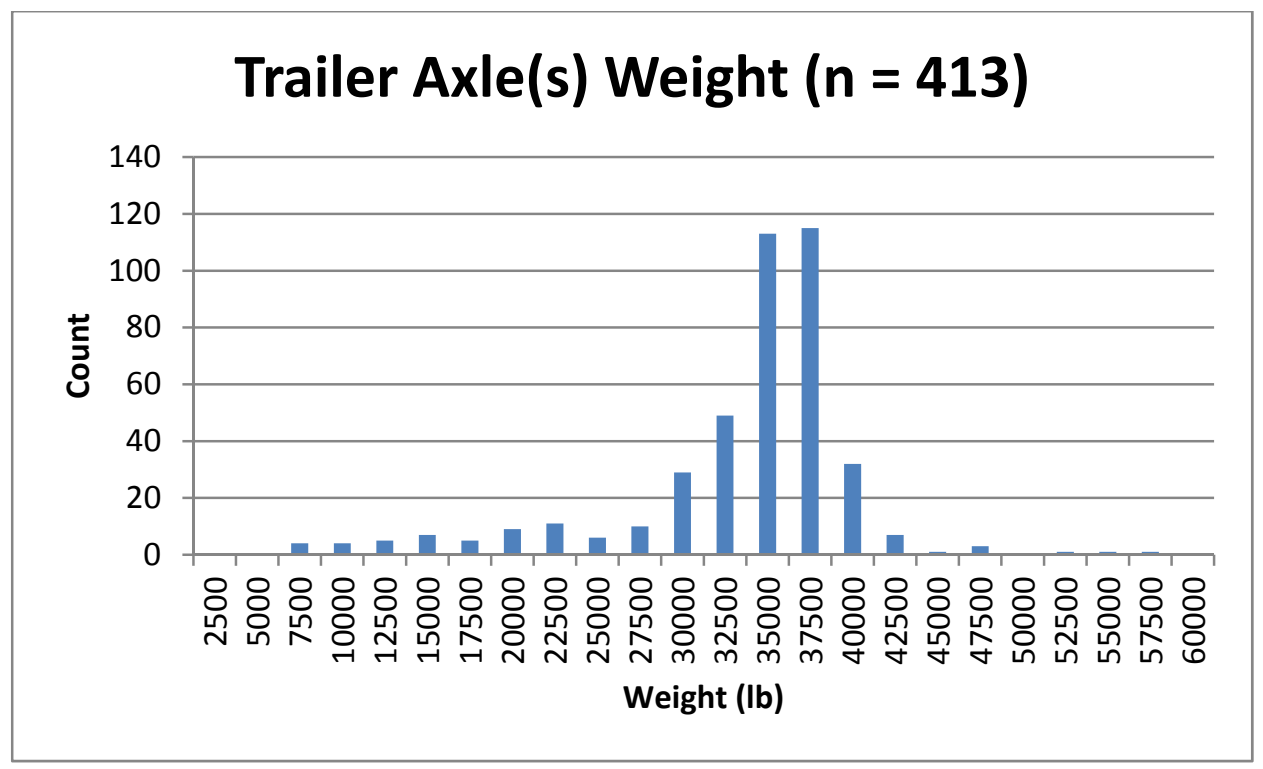

Figure 8. Tennessee Distribution of Trailer Weight

The location of an overweight axle when a vehicle's GVW is within the legal limit can give some insight regarding whether the trailer was properly loaded, whether the load may have shifted during travel, or whether the trailer's tandem axle was not properly positioned. Table 4 shows the general location of the axle overweight violations, how many vehicles were overweight gross, and how many had both types of overweight violations. The number of both trailer and drive axle overweight violations were similar while the number of gross overweight vehicles was substantially less. This suggests that in many of these instances a vehicle may not have been overweight if the load were better distributed on the trailer. Table 5 and Table 6 also show the average weight over on a specific axle or the average weight over gross. The average weight of each axle group and the average GVW, along with the average amount of weight over the legal limit, suggesting that improper loading of the trailer was indeed a major factor in a vehicle being overweight.

Table 4. Tennessee Overweight Location

\begin{tabular}{|c|rrr|r|r|}
\hline Axles & $\begin{array}{c}\text { Number } \\
\text { CMVs }\end{array}$ & $\begin{array}{c}\text { Overweight } \\
\text { Drive }\end{array}$ & $\begin{array}{c}\text { Overweight } \\
\text { Trailer }\end{array}$ & $\begin{array}{c}\text { Overweight } \\
\text { Gross }\end{array}$ & $\begin{array}{c}\text { Overweight Axle } \\
\text { \& Gross }\end{array}$ \\
\hline $\mathbf{2}$ & 2 & 2 & 0 & 1 & 1 \\
\hline $\mathbf{3}$ & 5 & 4 & 1 & 1 & 1 \\
\hline $\mathbf{4}$ & 10 & 8 & 1 & 2 & 66 \\
\hline $\mathbf{5}$ & 373 & 170 & 195 & 74 & 0 \\
\hline $\mathbf{6 +}$ & 5 & 1 & 0 & 2 & 0 \\
\hline $\mathbf{7}$ & 3 & 0 & 0 & 0 & 70 \\
\hline Total & 398 & 185 & 197 & 80 & \\
\hline
\end{tabular}


Table 5. Tennessee Average Weight Over Legal Limit

\begin{tabular}{|lcrc|}
\hline & Minimum & Average & Maximum \\
\hline Over on Axle & $20 \mathrm{lb}$ & $1,879 \mathrm{lb}$ & $12,160 \mathrm{lb}$ \\
\hline Over on Gross & $20 \mathrm{lb}$ & $1,497 \mathrm{lb}$ & $13,160 \mathrm{lb}$ \\
\hline
\end{tabular}

Table 6. Tennessee Average Weight Over Legal Limit, Specific Locations

\begin{tabular}{|lcc|}
\hline & Average Weight Over Limit & Average Weight \\
\hline Over on Drive & $1,757 \mathrm{lb}$ & $32,428 \mathrm{lb}$ \\
\hline Over on Trailer & $1,992 \mathrm{lb}$ & $32,207 \mathrm{lb}$ \\
\hline Over on Gross & $1,497 \mathrm{lb}$ & $77,321 \mathrm{lb}$ \\
\hline
\end{tabular}

Figure 9 and Figure 10 show the amount of weight over the legal axle group limit or over the legal GVW limit respectively. As previously shown in Table 4 the frequency of either the drive or trailer axles being overweight were almost the same. The trailer axle or group of axles on average were overweight by 200 lb more than the drive axle weight.

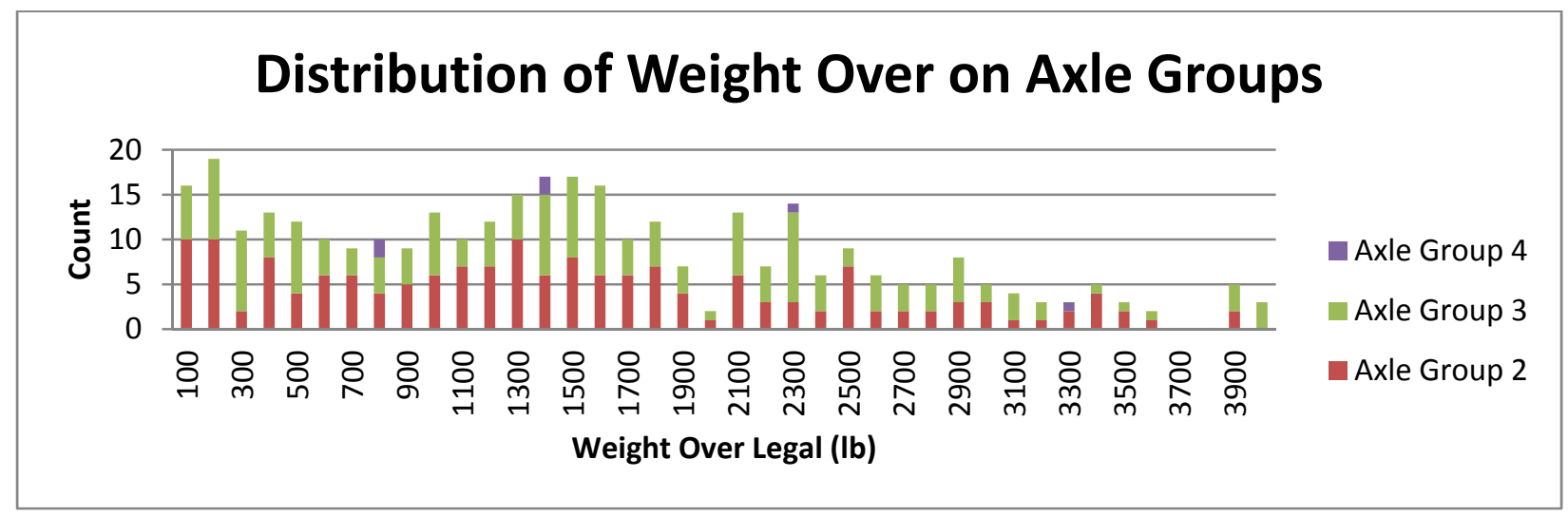

Figure 9. Tennessee Distribution of Weight Over on Axle Groups

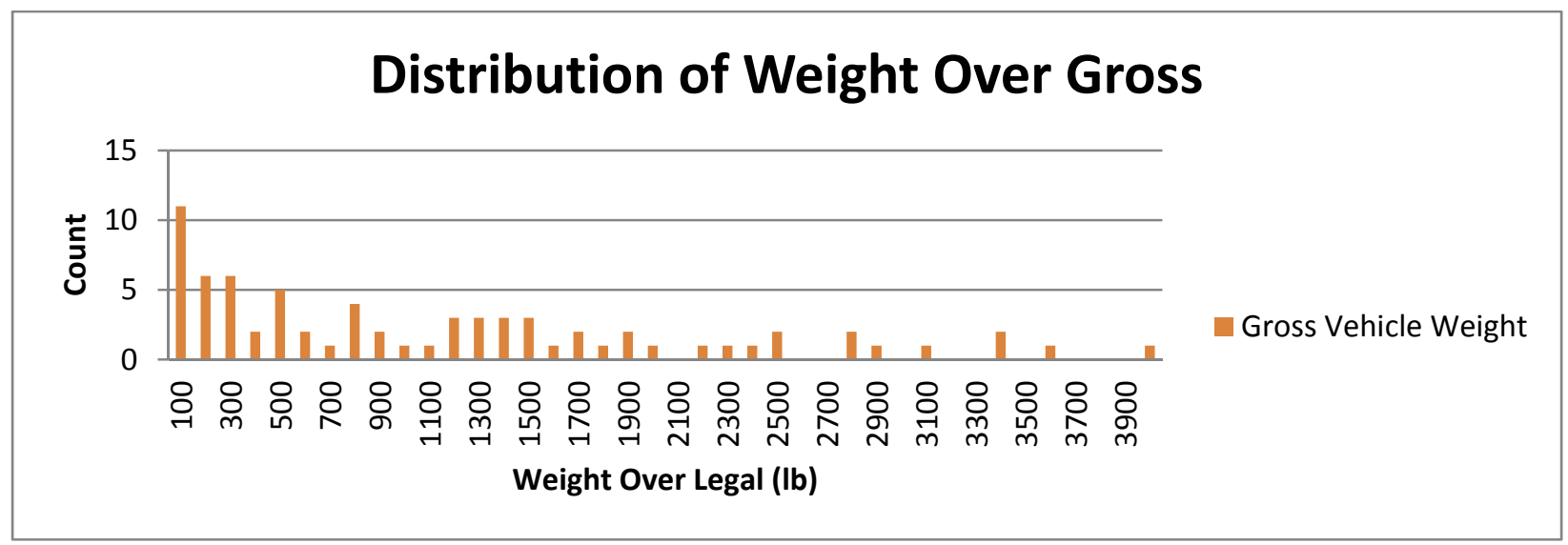

Figure 10. Tennessee Distribution of Weight Over Gross 
Table 7 shows the most common violations for the vehicles inspected in Tennessee as part of this effort. Brake violations represent the 6 most common violations while tire and wheel violations follow with substantially less violations.

Table 7. Tennessee Common Violations

\begin{tabular}{|c|c|c|}
\hline Violation Description & $\begin{array}{l}\text { Frequency } \\
\text { of Violation }\end{array}$ & Violation Code \\
\hline Clamp or Roto type brake out-of-adjustment & 112 & 393.47E \\
\hline Insufficient brake linings & 81 & 393.47D \\
\hline $\begin{array}{l}\text { CMV manufactured after } 10 / 19 / 94 \text { has an automatic airbrake } \\
\text { adjustment system that fails to compensate for wear }\end{array}$ & 64 & $393.53 B$ \\
\hline $\begin{array}{l}\text { Insufficient Braking Force as a Percentage of Gross Vehicle Weight or } \\
\text { Gross Combination Weight }\end{array}$ & 59 & 393.52A1 \\
\hline $\begin{array}{l}\text { BRAKES OUT OF SERVICE: The number of defective brakes is equal to } \\
\text { or greater than } 20 \text { percent of the service brakes on the vehicle or } \\
\text { combination }\end{array}$ & 44 & 396.3A1BOS \\
\hline Inoperative/defective brakes & 33 & $393.48 \mathrm{~A}$ \\
\hline License Plate violation & 31 & 392.2RG \\
\hline Tire-other tread depth less than $2 / 32$ of inch & 31 & $393.75 C$ \\
\hline Inspection, repair and maintenance of parts and accessories & 28 & 396.3A1 \\
\hline Hubs - oil and/or grease leaking from hub & 28 & 396.5B-HLIW \\
\hline Oil and/or grease leak & 26 & 396.5B \\
\hline Inoperative turn signal & 25 & 393.9TS \\
\hline Axle positioning parts defective/missing & 23 & $393.207 A$ \\
\hline Tire-tread and/or sidewall separation & 20 & $393.75 A 2$ \\
\hline Stop lamp violations & 17 & $393.25 \mathrm{~F}$ \\
\hline Operating a CMV without periodic inspection & 16 & $396.17 \mathrm{C}$ \\
\hline Brake connections with leaks or constrictions & 15 & $393.45 \mathrm{D}$ \\
\hline Inadequate brakes for safe stopping & 14 & $393.47 \mathrm{~A}$ \\
\hline Inoperable head lamps & 11 & $393.9 \mathrm{H}$ \\
\hline Inoperable required lamp & 11 & 393.9 \\
\hline
\end{tabular}

\subsection{NATIONWIDE OVERWEIGHT VEHICLE DEFECTS}

Eighteen states voluntarily participated in the CVSA data collection effort from January 2012 to July 2012. Table 8 shows the number of vehicle inspections for each state as well as the OOS rate for those inspections. Also shown are the OOS rates for 2011 for each state for comparison. Many of the states with a significant number of inspections (over 30) showed large increases in OOS rates compared to baseline 2011 OOS rates, i.e., as a whole there was an increase of $64.56 \%$ in OOS rate. 
Table 8. Nationwide Overweight Out-of-Service Rates

\begin{tabular}{|c|r|r|c|c|}
\hline State & $\begin{array}{r}\text { No. CMVs Overweight } \\
\text { Inspected }\end{array}$ & $\begin{array}{c}\text { No. CMVs Out of } \\
\text { Service }\end{array}$ & $\begin{array}{c}\text { CMV Out of Service } \\
\text { Rate }\end{array}$ & $\begin{array}{c}\text { CY2011 Out of } \\
\text { Service Rate }{ }^{2}\end{array}$ \\
\hline AK & 1 & 1 & $100.00 \%$ & $23.01 \%$ \\
\hline AL & 6 & 1 & $16.67 \%$ & $18.66 \%$ \\
\hline CT & 203 & 108 & $53.20 \%$ & $41.78 \%$ \\
\hline FL & 2 & 1 & $50.00 \%$ & $41.71 \%$ \\
\hline IL & 10 & 3 & $30.00 \%$ & $25.00 \%$ \\
\hline KS & 5 & 0 & $0.00 \%$ & $37.97 \%$ \\
\hline KY & 6 & 4 & $66.67 \%$ & $25.23 \%$ \\
\hline ME & 78 & 20 & $25.64 \%$ & $23.68 \%$ \\
\hline MT & 12 & 5 & $41.67 \%$ & $26.19 \%$ \\
\hline NC & 19 & 8 & $42.11 \%$ & $25.34 \%$ \\
\hline NE & 242 & 115 & $47.52 \%$ & $25.52 \%$ \\
\hline OK & 10 & 111 & $47.84 \%$ & $33.04 \%$ \\
\hline OR & 166 & 1 & $10.00 \%$ & $37.45 \%$ \\
\hline SC & 64 & 57 & $34.34 \%$ & $35.32 \%$ \\
\hline TN & 213 & 28 & $43.75 \%$ & $32.75 \%$ \\
\hline UT & 4 & 88 & $41.31 \%$ & $23.60 \%$ \\
\hline WA & 202 & 106 & $100.00 \%$ & $32.59 \%$ \\
\hline Total & $\mathbf{1 , 4 7}$ & 661 & $52.48 \%$ & $29.43 \%$ \\
\hline
\end{tabular}

Table 9 shows the amount of non-combination vehicles (commonly 2-axle straight trucks), and how many permitted vehicles were inspected. The majority of the vehicles inspected were non-permitted combination vehicles which representative of the majority of the vehicles on the interstate.

Table 9. Nationwide Detailed Out-of-Service Rates

\begin{tabular}{|c|r|c|c|c|c|}
\hline Combination CMV & No. CMVs & OOS Rate & Permitted CMV & No. CMVs & OOS Rate \\
\hline Yes & 1,229 & $45.40 \%$ & Yes & 258 & $32.56 \%$ \\
\hline No & 246 & $41.87 \%$ & No & 1,217 & $47.41 \%$ \\
\hline Total & $\mathbf{1 , 4 7 5}$ & $\mathbf{4 4 . 8 1 \%}$ & Total & $\mathbf{1 , 4 7 5}$ & $\mathbf{4 4 . 8 1 \%}$ \\
\hline
\end{tabular}

In order to determine if the high OOS rate could be because of historically problematic carriers being inspected, $\mathrm{CSA}^{3}$ vehicle maintenance ranks were examined for each state. Table 10 shows the number of inspections in each state that were above or below the $80^{\text {th }}$ percentile for CSA vehicle maintenance BASIC and also inspections where no rank was available. Being above the $80^{\text {th }}$ percentile means a carrier has a CSA vehicle maintenance BASIC higher than at least $80 \%$ of the other carriers. Likewise, being below the $80^{\text {th }}$ percentile means a carrier has a lower, or better, CSA vehicle maintenance BASIC than at

${ }^{2}$ OOS Rates retrieved from FMCSA Analysis \& Information Online. http://ai.fmcsa.dot.gov/

${ }^{3}$ CSA (Compliance, Safety, Accountability) is an FMCSA initiative to improve overall truck and bus safety, especially by reducing truck and bus related crashes, injuries and fatalities. http://csa.fmcsa.dot.gov/ 
least $20 \%$ of the other carriers; and no rank means the carrier does not have enough inspection data to have a CSA vehicle maintenance BASIC. It is clear that with the number of inspections where the carrier was below the $80^{\text {th }}$ percentile or the carrier had no rank, that the data is not being heavily skewed with vehicles that are expected to be OOS.

Table 10. Nationwide CSA Vehicle Maintenance BASIC Percentile Rank

\begin{tabular}{|crrr|}
\hline State & Above 80 & Below 80 & Not Ranked \\
\hline AK & 1 & 0 & 0 \\
\hline AL & 0 & 3 & 3 \\
\hline AR & 54 & 84 & 65 \\
\hline CT & 0 & 0 & 2 \\
\hline FL & 0 & 6 & 4 \\
\hline IL & 5 & 0 & 0 \\
\hline KS & 2 & 2 & 2 \\
\hline KY & 12 & 55 & 11 \\
\hline ME & 2 & 2 & 8 \\
\hline MT & 4 & 10 & 5 \\
\hline NC & 32 & 85 & 125 \\
\hline NE & 49 & 75 & 108 \\
\hline OK & 1 & 8 & 1 \\
\hline OR & 19 & 113 & 34 \\
\hline SC & 19 & 33 & 12 \\
\hline TN & 30 & 153 & 30 \\
\hline UT & 3 & 0 & 1 \\
\hline WA & 37 & 118 & 47 \\
\hline Total & 270 & 747 & 458 \\
\hline & & & \\
\hline & 270 & 0 & 12 \\
\hline
\end{tabular}

Table 11 shows the OOS rate for each vehicle maintenance rank range for the states which accounted for over $85 \%$ of the total inspections. The OOS rate for vehicles with a CSA vehicle maintenance BASIC above the $80^{\text {th }}$ percentile were OOS $66.06 \%$ of the time and vehicles with a ranking below the $80^{\text {th }}$ percentile and vehicles with no rank were OOS $35.99 \%$ and $52.08 \%$ of the time respectively. While it is expected that vehicles below the $80^{\text {th }}$ percentile would have a lower OOS rate than vehicles above, the OOS rate is still an increase of 32.17\% over the national average from 2011 (27.23\%) and even higher for vehicles with no rank. 
Table 11. Nationwide CSA Vehicle Maintenance BASIC Percentile Rank Out-of-Service Rates

\begin{tabular}{|ccccccccccc|}
\hline \multicolumn{3}{c}{} & \multicolumn{3}{c}{ Above $\mathbf{8 0}$} & \multicolumn{3}{c}{ Below $\mathbf{8 0}$} & \multicolumn{3}{c|}{ No Rank } \\
\hline State & $\begin{array}{c}\text { No. } \\
\text { CMVs }\end{array}$ & No. & OOS & $\begin{array}{c}\text { OOS } \\
\text { Rate }\end{array}$ & $\begin{array}{c}\text { No. } \\
\text { CMVs }\end{array}$ & $\begin{array}{c}\text { No. } \\
\text { OOS }\end{array}$ & $\begin{array}{c}\text { OOS } \\
\text { Rate }\end{array}$ & $\begin{array}{c}\text { No. } \\
\text { CMVs }\end{array}$ & $\begin{array}{c}\text { No. } \\
\text { OOS }\end{array}$ & $\begin{array}{c}\text { OOS } \\
\text { Rate }\end{array}$ \\
\hline AR & 54 & 34 & $62.96 \%$ & 84 & 30 & $35.71 \%$ & 65 & 44 & $67.69 \%$ \\
\hline NC & 32 & 20 & $62.50 \%$ & 85 & 29 & $34.12 \%$ & 125 & 66 & $52.80 \%$ \\
\hline NE & 49 & 33 & $67.35 \%$ & 75 & 21 & $28.00 \%$ & 108 & 57 & $52.78 \%$ \\
\hline OR & 19 & 10 & $52.63 \%$ & 113 & 37 & $32.74 \%$ & 34 & 10 & $29.41 \%$ \\
\hline TN & 30 & 20 & $66.67 \%$ & 153 & 55 & $35.95 \%$ & 30 & 13 & $43.33 \%$ \\
\hline WA & 37 & 29 & $78.38 \%$ & 118 & 54 & $45.76 \%$ & 47 & 23 & $48.94 \%$ \\
\hline Total & $\mathbf{2 2 1}$ & $\mathbf{1 4 6}$ & $\mathbf{6 6 . 0 6 \%}$ & $\mathbf{6 2 8}$ & $\mathbf{2 2 6}$ & $\mathbf{3 5 . 9 9 \%}$ & $\mathbf{4 0 9}$ & $\mathbf{2 1 3}$ & $\mathbf{5 2 . 0 8 \%}$ \\
\hline
\end{tabular}

Table 12 shows that similar to the CSA vehicle maintenance BASIC scores, the crash indicator scores show how many carriers with patterns or histories of high crash involvement, including frequency and severity, were represented in this set of data. Only about one third of the inspections had any type of crash score associated with them so it is inferred that the carriers that were inspected are not prone to many accidents even with possibly high vehicle maintenance scores.

Table 12. Nationwide CSA Crash Indicator Percentile Rank

\begin{tabular}{|c|r|r|r|}
\hline State & Above 60 & Below 60 & None \\
\hline AK & 0 & 0 & 1 \\
\hline AL & 0 & 0 & 6 \\
\hline AR & 29 & 52 & 122 \\
\hline CT & 0 & 0 & 2 \\
\hline FL & 2 & 3 & 5 \\
\hline IL & 0 & 5 & 0 \\
\hline KS & 1 & 1 & 4 \\
\hline KY & 19 & 29 & 30 \\
\hline ME & 0 & 1 & 11 \\
\hline MT & 0 & 8 & 11 \\
\hline NC & 14 & 37 & 191 \\
\hline NE & 16 & 40 & 176 \\
\hline OK & 1 & 6 & 3 \\
\hline OR & 15 & 46 & 105 \\
\hline SC & 14 & 19 & 31 \\
\hline TN & 42 & 96 & 75 \\
\hline UT & 0 & 0 & 4 \\
\hline WA & 17 & 45 & 140 \\
\hline Total & $\mathbf{1 7 0}$ & $\mathbf{3 8 8}$ & $\mathbf{9 1 7}$ \\
\hline
\end{tabular}

Brake problems are the most common vehicle-associated factor for large truck crashes, approximately 
$29 \%{ }^{4}$, and with extra force required to stop the vehicle, faulty brakes can potentially lead to even more crashes. Shown in Table 13 are the primary reasons a vehicle was placed OOS. Brakes related violations account for $67.47 \%$ of all the OOS vehicles and the rest being mainly tire violations and Other violations (mainly lamp-related violations). Similarly, Table 14 shows how often each type of OOS violation occurred and how many vehicles were placed OOS for that category of violation, even if a secondary violation. Brake related violations account for $50.82 \%$ of all OOS violations, tires $12.85 \%$ and Other $30.68 \%$. Comparing the results from Table 13 and Table 14, it is clear than many of the vehicles inspected were placed OOS for more than a single violation type.

Table 13. Nationwide Primary Cause of Out-of-Service CMV

\begin{tabular}{|lrr|}
\hline Primary OOS Violation Type & No. of CMVs OOS & OOS Rate \\
\hline Brakes, All Others & 276 & $18.71 \%$ \\
\hline Brakes, Adjustment & 170 & $11.53 \%$ \\
\hline Tires & 72 & $4.88 \%$ \\
\hline Suspension & 17 & $1.15 \%$ \\
\hline Wheels & 7 & $0.47 \%$ \\
\hline Other & 119 & $8.07 \%$ \\
\hline Total (out of $\mathbf{1 , 4 7 5}$ CMVs) & $\mathbf{6 6 1}$ & $\mathbf{4 4 . 8 1 \%}$ \\
\hline
\end{tabular}

Table 14. Nationwide Out-of-Service Violations

\begin{tabular}{|lcc|}
\hline OOS Violation Type & No. of CMVs OOS & Number Total OOS Violations \\
\hline Brakes, All Others & 276 & 688 \\
\hline Brakes, Adjustment & 270 & 455 \\
\hline Tires & 129 & 289 \\
\hline Suspension & 37 & 77 \\
\hline Wheels & 26 & 50 \\
\hline Other & 292 & 690 \\
\hline Total (out of $\mathbf{1 4 7 5}$ CMVs) & & $\mathbf{2 , 2 4 9}$ \\
\hline
\end{tabular}

Table 15 simply shows the most common violations and how often they occurred. The most common brake-related violations were adjustment, hose, or brake lining related. Common tire violations included exceeding tire load limit, flat tires, and insufficient tire tread. All of these violations, especially with heavy vehicles, greatly increase the likelihood of a vehicle not being able to stop in a timely manner, or not having full control of a vehicle in the event of an emergency stop or maneuver, especially in inclement weather. Also shown in the table is the rate of which each violation occurs as a percent of the total number of inspections. When compared to the national average, it is clear that overweight vehicles are more likely to have an OOS violation than vehicles that are no overweight.

\footnotetext{
${ }^{4}$ U.S. Department of Transportation Federal Motor Carrier Safety Administration, Report to Congress on the Large Truck Crash Causation Study. March 2006.
} 
Table 15. Nationwide Common Out-of-Service Violations

\begin{tabular}{|c|c|c|c|}
\hline OOS Violation & $\begin{array}{l}\text { Frequency of } \\
\text { Violation }\end{array}$ & $\begin{array}{l}\text { Violation } \\
\text { Rate* }\end{array}$ & $\begin{array}{l}\text { CY } 2011 \\
\text { National Rate* }\end{array}$ \\
\hline $20 \%$ Criteria & 454 & $30.78 \%$ & N/A \\
\hline Inoperative/defective brakes & 164 & $11.12 \%$ & $1.13 \%$ \\
\hline $\begin{array}{l}\text { Inspection/repair and maintenance parts \& } \\
\text { accessories }\end{array}$ & 120 & $8.14 \%$ & $1.36 \%$ \\
\hline Inoperative turn signal & 104 & $7.05 \%$ & $1.67 \%$ \\
\hline Insufficient braking force as \% of GVW or GCW & 100 & $6.78 \%$ & $0.02 \%$ \\
\hline Brake tubing and hose adequacy & 91 & $6.17 \%$ & $1.46 \%$ \\
\hline Insufficient Brake Linings & 82 & $5.56 \%$ & $0.21 \%$ \\
\hline Weight carried exceeds tire load limit & 74 & $5.02 \%$ & $0.01 \%$ \\
\hline Axle positioning parts defective / missing & 74 & $5.02 \%$ & $0.71 \%$ \\
\hline Stop lamp violations & 69 & $4.68 \%$ & $1.21 \%$ \\
\hline Flat tire or fabric exposed & 62 & $4.20 \%$ & $1.53 \%$ \\
\hline Air suspension pressure loss & 54 & $3.66 \%$ & $0.28 \%$ \\
\hline $\begin{array}{l}\text { Inadequate brakes for safe stopping (Brake } \\
\text { components) }\end{array}$ & 51 & $3.46 \%$ & $0.41 \%$ \\
\hline Tire-flat and/or audible air leak & 43 & $2.92 \%$ & $1.32 \%$ \\
\hline Tire-other tread depth less than $2 / 32$ of inch & 37 & $2.51 \%$ & $0.78 \%$ \\
\hline Leaking/spilling/blowing/falling cargo & 30 & $2.03 \%$ & $0.39 \%$ \\
\hline Brakes (general) & 28 & $1.90 \%$ & $0.30 \%$ \\
\hline Bake Hose/Tubing Chaffing and/or Kinking & 27 & $1.83 \%$ & $0.45 \%$ \\
\hline $\begin{array}{l}\text { Steering system components } \\
\text { worn/welded/missing }\end{array}$ & 25 & $1.69 \%$ & $0.48 \%$ \\
\hline No/improper breakaway or emergency braking & 25 & $1.69 \%$ & $1.18 \%$ \\
\hline
\end{tabular}

*Violation rate calculated by number of OOS violations divided by total number of inspections (Includes both Level I and II inspections).

Figure 11 displays the distribution of GVW of the inspected vehicles in which weight was recorded. The majority of the vehicles weighed between 75,000 lb and 85,000 lb, which can be expected with carriers trying to maximize the amount of product they can haul. While many of these vehicles were likely not over the maximum weight their equipment could support, they were over the legal limit based on the Bridge Formula Weights. 


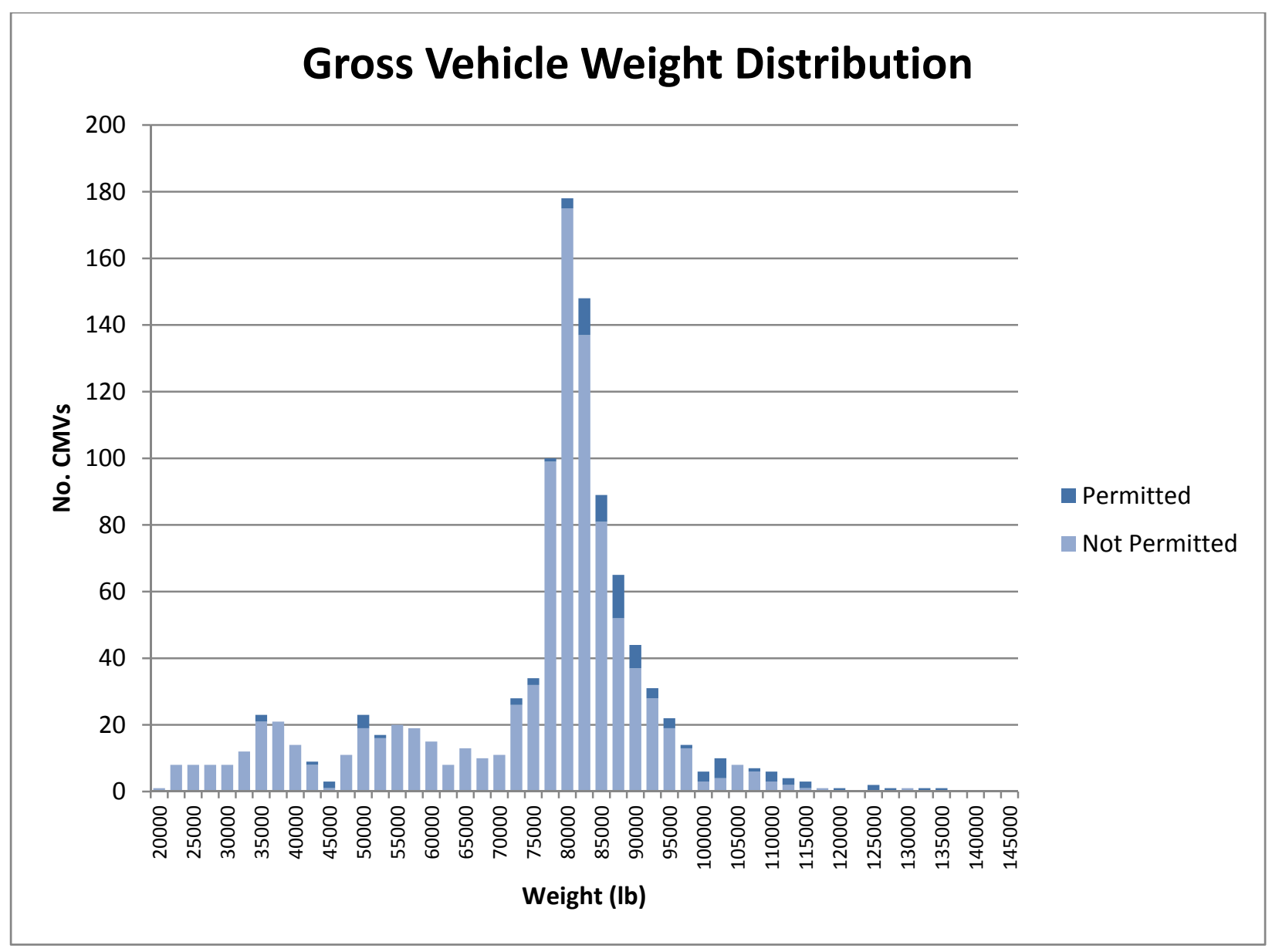

Figure 11. Nationwide Distribution of Gross Vehicle Weight

Figure 12 shows the OOS rate as a function of weight for non-permitted vehicles. While there is no immediate trend, there is a somewhat noticeable drop in the OOS rate for vehicles in the 75,000 lb to $85,000 \mathrm{lb}$ weight range. This can likely be attributed to the larger number of vehicles in those weight ranges, so while the rate of OOS vehicles is lower, the number of OOS vehicles is higher. In nearly all cases, the OOS rate was higher than the 2011 average of $27.23 \%$. 


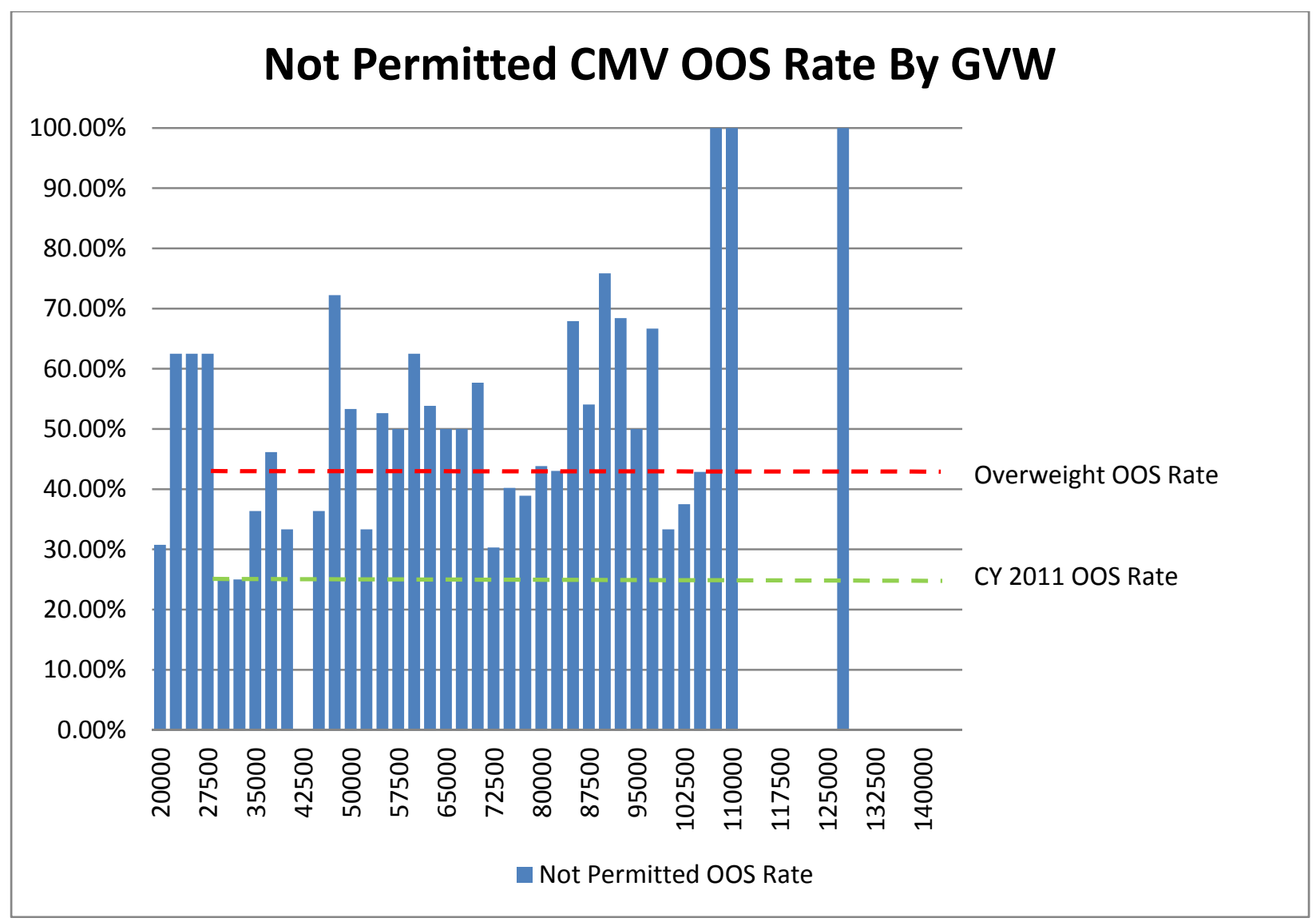

Figure 12. Nationwide Out-of-Service Rate by Gross Vehicle Weight

Since not every state has the same weight laws, a citation may not be written for a vehicle even if it was declared overweight as part of this data collection effort. Table 16 shows specific weight violations and corresponding OOS rates. Violations 392.2-SLLEWA1-3 describe vehicles that were overweight on an axle group while violations 392.2-SLLEWG1-3 describe vehicles overweight gross. Violation 392.2W is a general overweight violation and typically is given for overweight gross. With the exception of $392.2 \mathrm{~W}$, all the violations had nearly a $50 \%$ OOS rate.

Table 16. Nationwide Out-of-Service Rate of Vehicles With Weight Violations

\begin{tabular}{|lrcc|}
\hline \multicolumn{1}{|c}{ Violation } & No. CMVs & No. CMVs OOS & OOS Rate \\
\hline 392.2 W & 52 & 19 & $36.54 \%$ \\
\hline 392.2-SLLEWA1 & 186 & 91 & $48.92 \%$ \\
\hline 392.2-SLLEWA2 & 98 & 55 & $56.12 \%$ \\
\hline 392.2 -SLLEWA3 & 41 & 23 & $56.10 \%$ \\
\hline 392.2-SLLEWG1 & 41 & 20 & $48.78 \%$ \\
\hline 392.2-SLLEWG2 & 41 & 26 & $63.41 \%$ \\
\hline 392.2-SLLEWG3 & 35 & 20 & $57.14 \%$ \\
\hline Total & $\mathbf{4 9 4}$ & $\mathbf{2 5 4}$ & $\mathbf{5 1 . 4 2 \%}$ \\
\hline
\end{tabular}




\section{CONCLUSIONS}

The data collected thus far suggests a correlation between vehicle equipment violations, weight and thus safety. It may not be safe to assume that a vehicle found to be overweight as part of this data collection effort is overweight on every load they haul, but it can be inferred that vehicles that tend to be overweight occasionally are lacking proper vehicle maintenance.

Of the 1,873 Level I inspections performed over the past six months in 18 different states, $44.79 \%$ of CMVs had a vehicle OOS violation. With the national average being only $27.23 \%$, this is significantly high in comparison. While the inspections performed may not entirely represent the entire stream of overweight vehicles, the selection protocol does coincide with normal operation, so the data collected can be compared with national averages. Also, from the Tennessee specific data in Section 3.1, there was a significant increase in the OOS rate of overweight vehicles compared to national and state averages, however because of different selection methodologies, these findings may not be suitable for a direct comparison.

Since more force is required to stop or slow a vehicle in the same distance and time as the weight of the vehicle increases, brakes (as well as other vehicle components) being in proper working condition is important in order to reduce the potential for crashes. Brake violations were the most common violation for OOS vehicles which suggests that heavy vehicles do tend to have worn or faulty brakes more often than vehicles that are not overweight. Tire violations were also common among the OOS vehicles. Suspension and wheel violations were not as common as the tire and brake violations, with only about $4 \%$ of OOS vehicles having either type of violation.

It has been determined from both efforts that it is much more likely for a vehicle to be overweight on an axle as opposed to a vehicle being over the legal GVW. The incidence of overweight axles is due mainly to poor load placement or improper adjustment of a trailer's tandem axle. Since states have different weight laws, not all inspections had a weight violation associated with them, however vehicles with a weight violation were OOS $51.42 \%$ of the time, while vehicles without a weight violation were OOS only $41.49 \%$ of the time. 


\section{FUTURE WORK}

The CVSA data collection effort is scheduled to continue through January 2013 with hopes of collecting more data from additional states as well as currently-participating states. With the larger set of data and the findings from this interim report, it is expected that a more conclusive answer can be found to the question of whether overweight and heavy vehicles are potentially more unsafe compared to vehicles operating within the legal weight limit for non-permitted vehicles.

Also, up to three states will be selected to participate in a data collection effort using the same online form used in the Tennessee data collection effort. This will provide additional information that is not normally available from Aspen reports such as individual axle weight. It is suggested that prior to collection of any overweight data, the states participating in this more detailed effort to collect inspection data using random selection methodology to get a baseline OOS rate for the specific stream of vehicles in that state.

ORNL is developing an online tool to provide relevant analysis of the CVSA data as soon as it is received. With this tool, federal and state enforcement and researchers will be able to view inspections, OOS rates and violations, and perform specific analysis on a national, state and county level. The interface for this online tool is shown in Figure 13 below.

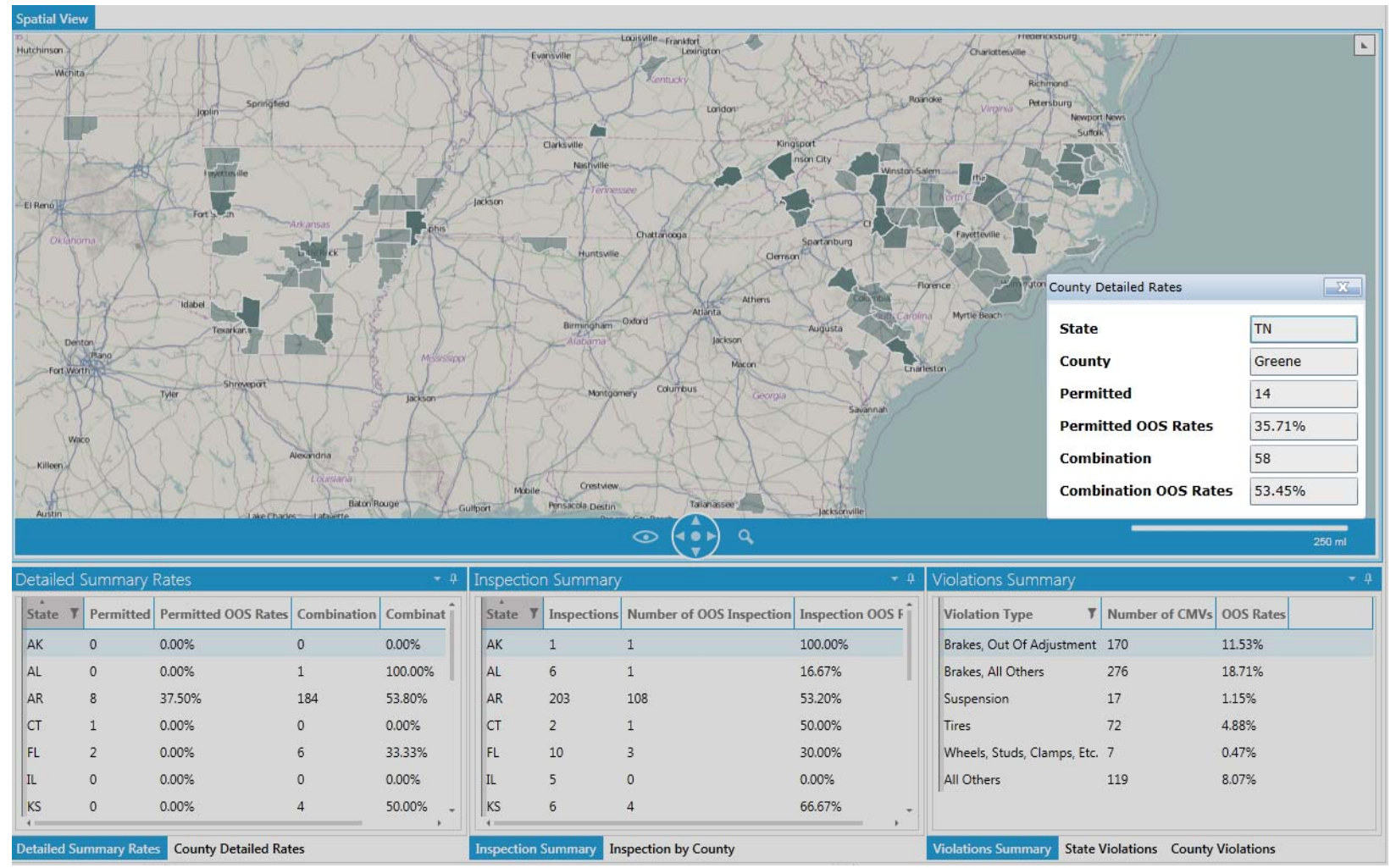

Figure 13. ORNL-Developed Online Analysis Tool 